\title{
Threshold influence on vibrotactile magnitude production scaling
}

\author{
LINDA PETROSINO, DONALD FUCCI, and DANIEL HARRIS \\ Ohio University, Athens, Ohio
}

\begin{abstract}
The present investigation attempted to look at possible influences that the obtainment of vibrotactile threshold might have on the power function exponent derived from magnitude production scaling. Two groups of six subjects each provided vibrotactile magnitude functions for the lingual dorsum and thenar eminence of the right hand. Group 1 was required to provide a series of vibrotactile thresholds on the test structures prior to scaling. Group 2 performed the scaling task only. Results showed that the inclusion of the threshold task within the test paradigm had no influence on the subsequent scaling activity.
\end{abstract}

The present literature on neurophysiological mechanisms of cutaneous mechanoreception includes a significant amount of research concerned with suprathreshold levels of stimulation. These studies were initially performed to gain a better understanding of audition (Békésy, 1960) and to aid in the development of cutaneous communication systems (Geldard, 1961). Stevens (1961) performed a series of investigations relating subjective responses to stimulus intensities. Using the methods of magnitude estimation and production, he demonstrated that a power law function successfully describes the relationship between subjective intensity and the amplitude of vibration at the fingertip (Stevens, 1957). More recently, several researchers have begun to systematically study the various parameters that can have an effect on suprathreshold power functions (M. Teghtsoonian \& R. Teghtsoonian, 1971, 1983; R. Teghtsoonian, 1973; Verrillo, 1979, 1983; Verrillo \& Capraro, 1975; Verrillo \& Chamberlain, 1972; Verrillo, Fraioli, \& Smith, 1969; Verrillo \& Smith, 1976; Zwislocki \& Goodman, 1980).

Within the past 2 years, a series of studies has been performed in which vibrotactile magnitude production scaling was utilized with the dorsum of the human tongue as the site of stimulation. All of these studies were designed to determine those factors that might influence scaling behavior of the tongue. The factors that have received careful attention are: the nature of the lingual magnitude function and its differences with respect to male and female subjects (Fucci \& Petrosino, $1983 \mathrm{c}$ ); comparison of magnitude function curves for the tongue and hand (Fucci \& Petrosino, 1983a); the influence of age on lingual vibrotactile scaling (Fucci \& Petrosino, 1983b); the effect of contactor size, frequency, and range on lingual vibrotactile magnitude functions (Fucci, Harris, \& Petrosino, 1983a; Fucci \& Petrosino, 1982; Fucci, Petrosino, \& Harris, 1983);

The authors' mailing address is: School of Hearing and Speech Sciences, Ohio University, Athens, Ohio 45701. and the stability of lingual vibrotactile scaling mechanisms (Fucci, Harris, \& Petrosino, 1983b).

The feeling of vibration on the lingual dorsal surface is experienced by subjects as a unique perceptual event. They are accustomed to feeling vibrations on the hand as a matter of routine daily occurrences, but the tongue is different in this respect. Consequently, every subject in all of the scaling studies performed on the tongue received initial training at threshold levels by being required to provide consistent lingual vibrotactile thresholds prior to receiving instructions for the magnitude production scaling task. During the scaling task, many subjects inquired as to whether or not they should "refer back" to their threshold of sensitivity as a reference point for establishing the magnitude of the stimulus that they were about to scale. In every instance in which this question was asked, the subject involved was instructed to ignore the threshold information and to simply adjust the magnitude of the stimulus that he or she was feeling to the number being presented.

It is possible that the subjects involved in the lingual vibrotactile scaling studies used their threshold training experiences to establish a referent or modulus for scaling purposes. There is a certain body of literature that is concerned with the effect that inclusion of a referent or modulus has on the power function that results from suprathreshold magnitude scaling (Hellman \& Zwislocki, 1961, 1963; Verrillo et al., 1969;Zwislocki \& Goodman, 1980). In auditory experiments, subjects appear to favor moderate intensity levels and tend to select numbers that center about the designated standard (Stevens, 1956). Reynolds and Stevens (1960) showed that use of a standard referent reduces size of the power function exponent when it is incorporated into magnitude production scaling procedure. The purpose of the present investigation was to determine the possible effect of threshold obtainment, and the training it provides, on vibrotactile magnitude production scaling for the lingual dorsum and the thenar eminence of the right hand. 


\section{METHOD}

The vibrotactile instrumentation consisted of a stimulus unit and a measurement unit. The stimulus unit was composed of a sine-wave generator, an experimenter-controlled variable attenuator, a subject-controlled attenuator, two universal timers, an audio amplifier, a power amplifier, a preamplifier, and an electromagnetic minivibrator with a probe-contactor extension. The pulsed vibratory signal generated was $250 \mathrm{~Hz}$, with a $50 \%$ duty cycle (on $500 \mathrm{msec}$ and off $500 \mathrm{msec}$ ) and a rise-and-decay time of $100 \mathrm{msec}$. The measurement unit included an accelerometer, a cathode follower, a microphone amplifier, and a voltmeter. A detailed description of the vibrotactile equipment and procedures can be found in a review by Fucci, Petrosino, Wallace, and Small (1982).

Two groups of subjects were used in this study. Group 1 consisted of six adults (two males and four females) ranging in age from 19 to 24 years, with a mean age of 22 years. Group 2 consisted of six adults (two males and four females) ranging in age from 16 to 24 years, with a mean age of 21 years. None of the subjects reported histories of health problems, and none of the subjects had ever participated in vibrotactile testing of any kind. The subjects in both groups attended four test sessions separated by 1-week intervals, which were matched in terms of morning, afternoon, or evening participation. A series of three vibrotactile thresholds was taken for each test structure, prior to initiation of any suprathreshold scaling attempts, from the subjects in Group 1. The method of limits was used to obtain these thresholds, and new thresholds were obtained for each test structure in each of the four test sessions. Group 2 was introduced directly into suprathreshold scaling technique, and threshold was not measured or discussed. Aside from the taking of thresholds for Group 1, both groups were treated in the same manner for all four sessions. In each session, the subject was seated in an adjustable chair and was asked to place his or her tongue or the thenar eminence of the right hand up against the bottom of a rigidly mounted plastic disk. A hole in the center of the disk provided access for the probe-contactor extension of the vibrator to the structure being tested. The contactor on the end of the probe had an area of $.128 \mathrm{~cm}^{2}$, and there was a $1-\mathrm{mm}$ gap between the contactor and the plastic disk. The order of testing the tongue and thenar eminence was counterbalanced between subjects for all test sessions.

The psychophysical method of magnitude production was used to establish suprathreshold magnitude functions for the tongue and thenar eminence. This method was selected because it had been shown to be very stable (Zwislocki \& Goodman, 1980). The procedure used did not incorporate a standard modulus. The subject was presented with a random series of six numbers $(5,10,15,20,25,30)$ and was asked to adjust the "magnitude" of the stimulus that he or she was feeling on the tongue or the thenar eminence to the number being presented. The subject-controlled attenuator consisted of a smooth, unmarked knob (120-dB variable potentiometer) that provided no visual or mechanical cues. The experimenter was in control of a master attenuator that could be used to vary the actual stimulus amplitude with respect to the position of the subject's attenuator knob (Zwislocki \& Goodman, 1980). The numbers chosen for scaling were held to six because of adaptability and fatigue effects, which appear to be more acute for the tongue than for some of the other mechanoreceptor systems that have been studied (Fucci \& Crary, 1979).

Three runs of the randomized series of six numbers were presented to each subject for both test structures in each of the four sessions. The first run was discarded, and the geometric means of the second and third runs were accepted as the produced amplitudes (Verrillo et al., 1969). The results of the magnitude production task were recorded in millivolts and converted to displacement in decibels re 1-micron peak. Power function exponents were then derived from the decibel values.

\section{RESULTS AND DISCUSSION}

Table 1 shows Group 1 (threshold) and Group 2 (no threshold) mean slope values for the tongue and thenar eminence for all four test sessions. The slope values were calculated in terms of power. $T$ tests for a difference between two independent means were performed on the mean slope values of Group 1 and Group 2 for each test session. The $t$ values obtained were nonsignificant for all four of the test sessions, indicating that there were no statistically significant differences between group slope means for any of the test sessions.

The results obtained from this study suggest that threshold acquisition prior to magnitude scaling has no statistically significant effect on the slopes generated from the scaling procedure. The two activities appear to be unrelated even when performed in the same test session. Perhaps this lack of an effect of threshold procedure on scaling can be attributed to the nature of the tasks and the responses required of the subject. The threshold task requires the subject to indicate when the vibratory stimulus first becomes perceivable. This activity corresponds to the integrity of the sensory receptors. The scaling task requires the subject to relate a physical intensity to a subjective magnitude elicited through a number presented by the experimenter. This type of activity requires that a central perceptual process occur before a response is elicited (Gescheider, 1976; Savage, 1970).

There is the possibility that both groups of subjects were cognizant of their oral and nonoral vibrotactile thresholds and that both groups used this information to perform the magnitude production scaling in a similar manner. The subjects in Group 2 may have been just as aware of their thresholds of sensitivity as the subjects in Group 1, even though they were not required to provide threshold information to the experimenter through a formal testing procedure. Only the subjects in Group 1 inquired about using the threshold information as a zero baseline for scaling, but since threshold

Table 1

Group 1 (Threshold) and Group 2 (No Threshold) Mean Slope Values for the Tongue and Thenar Eminence

\begin{tabular}{|c|c|c|c|c|c|c|c|c|}
\hline \multirow[b]{2}{*}{ Group } & \multicolumn{4}{|c|}{ Tongue } & \multicolumn{4}{|c|}{ Thenar Eminence } \\
\hline & Session 1 & Session 2 & Session 3 & Session 4 & Session 1 & Session 2 & Session 3 & Session 4 \\
\hline $\begin{array}{l}\text { Group } 1 \\
\text { Group } 2\end{array}$ & $\begin{array}{l}.77 \\
.72\end{array}$ & $\begin{array}{l}.79 \\
.63\end{array}$ & $\begin{array}{l}.95 \\
.83 \\
\end{array}$ & $\begin{array}{l}.74 \\
.76 \\
\end{array}$ & $\begin{array}{l}.69 \\
.79 \\
\end{array}$ & $\begin{array}{l}.93 \\
.76 \\
\end{array}$ & $\begin{array}{l}.79 \\
.75 \\
\end{array}$ & $\begin{array}{l}.77 \\
.93 \\
\end{array}$ \\
\hline
\end{tabular}


was never mentioned to the Group 2 subjects, they simply might not have known how to inquire about its application to the scaling in which they were involved. The design incorporated into the present study did not take the possibility of "implied" threshold of sensitivity into account.

The inclusion of threshold tasks in oral and nonoral vibrotactile experiments that emphasize magnitude scaling is apparently an activity that can be performed without having an overall effect on the scaling procedure itself. The knowledge that threshold acquisition will not have an effect on scaling allows for flexibility within psychophysical experimental paradigms. For example, the experimenter can take the liberty of using the threshold technique as needed. It can be employed to train hard to test subjects such as young children, the elderly, or various handicapped individuals who can be better oriented to vibratory experimentation through the establishment of threshold. The experimenter can also choose to delete threshold measurement from the testing situation when it is not beneficial to subject orientation or pertinent to the overall design of the experiment.

\section{REFERENCES}

BÉKÉSY, G. von. (1960). Experiments in hearing. New York: McGraw-Hill.

Fucci, D., \& Crary, M. A. (1979). Oral vibrotactile sensation and perception: State of the art. In N. J. Lass (Ed.), Speech and language: Advances in basic research and practice (Vol. 2). New York: Academic Press.

Fucci, D., Harris, D., \& Petrosino, L. (1983a). The effect of contractor area on vibrotactile magnitude function exponents for the tongue and hand. Bulletin of the Psychonomic Society, 21, 400-402.

Fucci, D., Harris, D., \& Petrosino, L. (1983b). Stability of magnitude production scales for lingual vibrotactile sensation. Perceptual and Motor Skills, 57, 499-504.

Fucci, D., \& Petrosino, L. (1982). Lingual vibrotactile sensation magnitudes: Stimulus frequency effect. Bulletin of the Psychonomic Society, 20, 224-226.

Fucci, D., \& Petrosino, L. (1983a). Lingual vibrotactile sensation magnitudes: Comparison of suprathreshold responses for the tongue and hand. Journal of the Acoustical Society of America, 74, 351-353.

Fucci, D., \& Petrosino, L. (1983b). Lingual vibrotactile sensation magnitudes: Comparison of suprathreshold responses for three different age ranges. Perceptual and Motor Skills, 57, 31-38.

Fucci, D., \& Petrosino, L. (1983c). Lingual vibrotactile sensation magnitudes: Comparison of suprathreshold responses in men and women. Perception \& Psychophysics, 33, 93-95.

Fucci, D., Petrosino, L., \& Harris, D. (1983). Influence of scaling range on vibrotactile power function exponents for the tongue and hand. Perceptual and Motor Skills, 57, 642.

Fucci, D., Petrosino, L., Wallace, D., \& Small, L. (1982). Modification of instrumentation for research on lingual vibrotactile sensitivity: Elimination of the tongue clamping procedure. Review of Scientific Instruments, 53, 1294-1296.

GeldARD, F. A. (1961). Cutaneous channels of communication. In W. A. Rosenblith (Ed.), Sensory communication. New York: Wiley.

Gescheider, G. (1976). Psychophysics: Method and theory. Hillsdale, NJ: Erlbaum.

Hellman, R. P., \& Zwislocki, J. (1961). Some factors affecting the estimation of loudness. Journal of the Acoustical Society of America, 33, 687-694.

Hellman, R. P., \& Zwislocki, J. (1963). Monaural loudness function at $1000 \mathrm{cps}$ and interaural stimulation. Journal of the Acoustical Society of America, 35, 856-865.

Reynolds, G. S., \& Stevens, S. S. (1960). Binaural summation of loudness. Journal of the Acoustical Society of America, 32, 1337-1344.

Savage, C. W. (1970). THe measurement of sensation. Berkeley, CA: University of California Press.

STEvens, S. S. (1956). The direct estimation of sensory magnitudeloudness. American Journal of Psychology, 69, 1-25.

Stevens, S. S. (1957). On the psychological law. Psychological Review, 64, 153-181.

STEVENS, S. S. (1961). The psychophysics of sensory function. In W. A. Rosenblith (Ed.), Sensory communication. New York: Wiley.

Teghtsoonian, M., \& Teghtsoonian, R. (1971). How repeatable are Stevens's power law exponents for individual subjects? Perception \& Psychophysics, 10, 147-149.

Teghtsoonian, M., \& Teghtsoonian, R. (1983). Consistency of individual exponents in cross-modal matching. Perception \& Psychophysics, 33, 203-214.

Teghtsoonian, R. (1973). Range effects in psychophysical scaling and a revision of Stevens's law. American Journal of Psychology, 86, 3-27.

VERRILLO, R. T. (1979). Comparison of vibrotactile threshold and suprathreshold responses in men and women. Perception \&Psychophysics, 26, 20-24.

VERRILLO, R. T. (1983). Stability of line-length estimates using the method of absolute magnitude estimation. Perception \& Psychophysics, 33, 261-265.

Verrillo, R. T., \& Capraro, A. (1975). Effects of stimulus magnitude functions. Perception \& Psychophysics, 17, 91-96.

Verrillo, R. T., \& Chamberlain, S. C. (1972). The effect of neural density and contactor surround on vibrotactile sensation magnitude. Perception \& Psychophysics, 11, 117-120.

Verrillo, R. T., Fraioli, A. J., \& SMith, R. L. (1969). Sensation magnitude of vibrotactile stimuli. Perception \& Psychophysics, 6, 366-372.

Verrillo, R. T., \& SMith, R. (1976). Effects of stimulus duration on vibrotactile sensation magnitude. Bulletin of the Psychonomic Society, 8, 112-114.

Zwislocki, J., \& Goodman, D. (1980). Absolute scaling of sensory magnitudes: A validation. Perception \& Psychophysics, 28, 28-38.

(Manuscript received for publication November 9, 1983.) 